\title{
A Underwater Shield Tunnel External load Test Analysis Xiaoqiang Wang ${ }^{1, a}$, Huaifeng Tong ${ }^{2, b}$
}

School of Civil Engineering, Luoyang Institute of Science and Technology, Luoyang 471023,

\author{
P.R.China \\ awangxq08@163.com, btonghuaifeng@163.com
}

Key word: Shield tunnel; Monitoring; water and soil pressure

\begin{abstract}
A tunnel construction in a nuclear power plant is proposed in this paper. Some useful conclusions are drawn through the analysis of the measured results including the stress state and process of structure and water and soil pressure. It is useful for design, construction of similar engineering.
\end{abstract}

\section{Engineering survey}

Taishan nuclear power plant is the first EPR nuclear power plant in China; it is the world's largest single unit capacity of nuclear power. The maximum depth of the water intake tunnel is about $55.75 \mathrm{~m}$. The tunnel construction method uses shield method. The tunnel inner diameter is $7.3 \mathrm{~m}$, diameter is $8.7 \mathrm{~m}$, and the tunnel shield segments and two lining composite retaining structure. The shield segment thickness is $0.4 \mathrm{~m}$.

Site monitoring and analysis of shield segment The theoretical problems of tunnel lining design is the model itself can reflect the actual situation of the project. For such complex factors, the simple use of a computing theory is difficult to truly reflect the actual engineering, therefore, this article through the method of field measurement, researching the shield tunnel segment stress process and state, and the soil pressure around the tunnel.

Selection of monitoring section Monitoring section should be in the different overlying soil thickness and soil properties. Because the stability of IV, V and some kinds of third class III rocks is poor, and most of the type III and II class rock stability is generally good, therefore, the monitoring section is chosen in the IV and V rock stratum.

\section{Geological conditions of monitoring section}

Section I The monitoring section of No. 1 tunnel segment II is located in the 1690 ring, mileage DK2+687.85m. The depth of the tunnel is $25.52 \mathrm{~m}$, the depth of the bottom is $34.22 \mathrm{~m}$, and the depth of the sea water depth is about $3.34 \mathrm{~m}$. The clay layer tunnel is located mainly in the plastic to hard plastic, which belongs to the IV class surrounding rock.

Section II The monitoring section of No. 1 tunnel segment II is located in the 2049 ring, mileage $\mathrm{DK} 3+226.9 \mathrm{~m}$. The depth of the tunnel is $35.45 \mathrm{~m}$, the depth of the bottom is $44.15 \mathrm{~m}$, and the depth of the sea water depth is about $3.65 \mathrm{~m}$. The clay layer tunnel is located mainly in the plastic to hard plastic, which belongs to the IV class surrounding rock. The mechanical parameters of each layer are shown in Table 1.

Test method and frequency The sensor used in this test are vibrating wire type, the test data using JTM-V10B frequency meter, data using manual sampling.

After the segment assembly, depending on the speed of the shield tunneling and consider grouting pressure dissipates slowly, to reflect the construction process segment by force, need to adjust the data acquisition frequency. The formal measurement reading, it is usually at the beginning of each cycle of a ring to measure a reading, when reading changes in the larger, increase the test frequency. The reading change is not big, can reduce the measurement frequency; reading can be stopped after the stability monitoring. 
Table 1 statistical table of physical parameters of soil

\begin{tabular}{|c|c|c|c|c|c|c|c|}
\hline \multirow{2}{*}{$\begin{array}{c}\text { Layer } \\
\text { number }\end{array}$} & \multirow{2}{*}{ Name } & \multicolumn{2}{|c|}{$\begin{array}{c}\text { Density } \\
\left(\mathrm{g} / \mathrm{cm}^{3}\right)\end{array}$} & Saturation & $\begin{array}{c}\text { Cohesion } \\
(\mathrm{kPa})\end{array}$ & $\begin{array}{c}\text { Friction } \\
\text { angle }\left(^{\circ}\right)\end{array}$ & $\begin{array}{c}\text { Standard } \\
\text { penetration } \\
\text { test } \\
\text { blowcount(N) }\end{array}$ \\
\cline { 3 - 7 } & Wet & Dry & & & & 5.5 & 1 \\
\hline (2) & Mud & 1.56 & 0.89 & 15.64 & 4 & 5.1 & 2 \\
\hline (3) & Mud & 1.53 & 0.85 & 15.27 & 4.5 & 5.1 & 5 \\
\hline (4) & Silt clay & 1.72 & 1.17 & 17.32 & 11 & 8.5 & 5 \\
\hline (4)-1 & Gravel sand & 2.05 & 1.79 & 21 & - & 29 & 7 \\
\hline (4)-2 & $\begin{array}{c}\text { Silty sand mixed } \\
\text { silty clay }\end{array}$ & 2.00 & 1.64 & 20.18 & 12 & 20 & 7 \\
\hline (5) & Clay & 1.88 & 1.41 & 19.6 & 19 & 8.5 & 13 \\
\hline (5)-1 & Coarse gravel sand & 2.07 & 1.80 & 21.7 & - & 29 & 11 \\
\hline (6) & Coarse gravel sand & 2.07 & 1.82 & 21 & - & 30 & 18 \\
\hline 7) & Clay & 1.85 & 1.37 & 22 & 20 & 11.5 & 12 \\
\hline (8) & Clay & 1.95 & 1.53 & 22.2 & 22.5 & 7.0 & 15.2 \\
\hline (9) & Clay & 1.82 & 1.32 & 22.6 & 17.0 & 5.6 & 15.2 \\
\hline
\end{tabular}

\section{Monitoring results and analysis}

Water pressure monitoring results and analysis As shown in Figure 1, from the external water pressure curve graph, 429 ring and 845 ring monitoring sections, segment off the ring within six rings, synchronous grouting is at shield tail of the test value effect. After the 6 segment off the ring, the influence of shield tail synchronous grouting on the test results is obviously. The external water pressure is rapidly increased to the maximum water pressure $0.318 \sim 0.343 \mathrm{MPa}$, which is greater than that of the hydrostatic pressure. After the 6 ring of forward driving, the pressure of grouting is reduced, and the water pressure is reduced. The influence of sea water level changes on the water pressure of the whole lining is not particularly significant. The lining water pressure is developed according to the variation of its own. Known from the analysis of the measured data, the influence area of construction of external water pressure on lining approximately 5-18 rings, ring 20 almost entirely disappeared.

From the different monitoring section analysis, moderately deep buried section 845 rings and shallow buried section 429 rings, because of differences in the nature of soil around the segment larger, the measuring point, and a certain degree of volatility. This shows that the difference of the permeability coefficient of rock has a great influence on the distribution of water pressure.

From the whole dynamic change process, the water pressure of the tunnel lining is basically in a self balanced state of a small swing state, the basic will not appear big mutation.

Distribution law of water pressure in stable period From the specific test section, the section distribution of water pressure is seen in Fig. 2, the water pressure of the lining increases with the increase of the depth of the tunnel. This is also consistent with the distribution of seepage field in the tunnel area. Tunnel external water pressure is close to or equal to hydrostatic pressure, but due to the tunnel surrounding rock soil permeability difference, making the distribution of water pressure but also has a certain degree of randomness. 


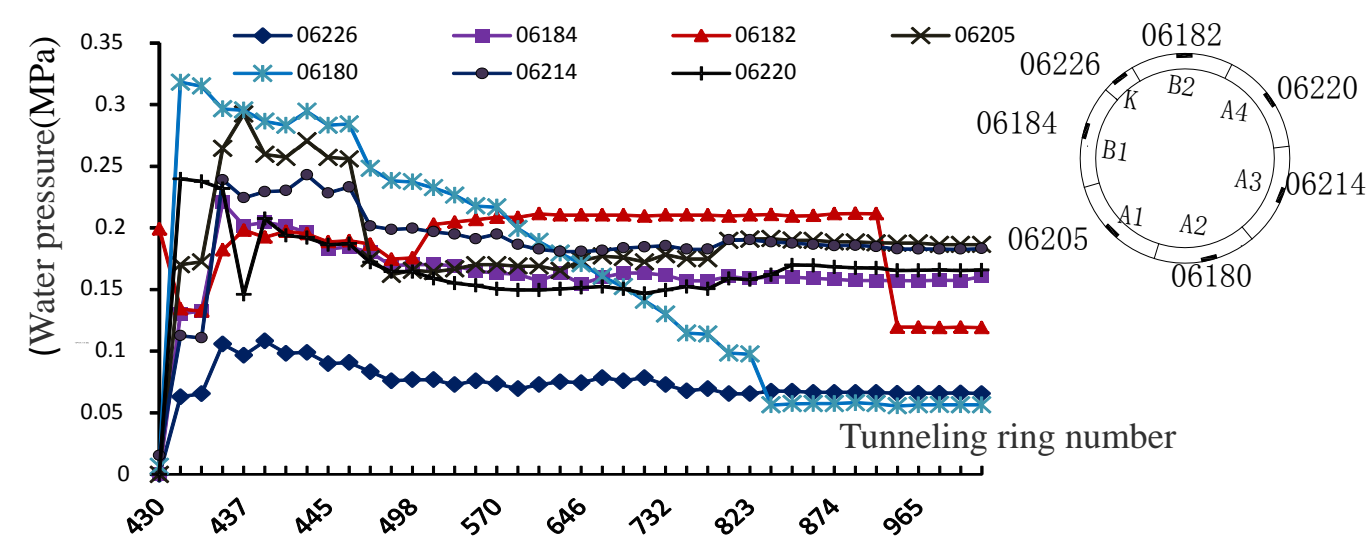

(a) 429 ring water pressure with time dynamic curve

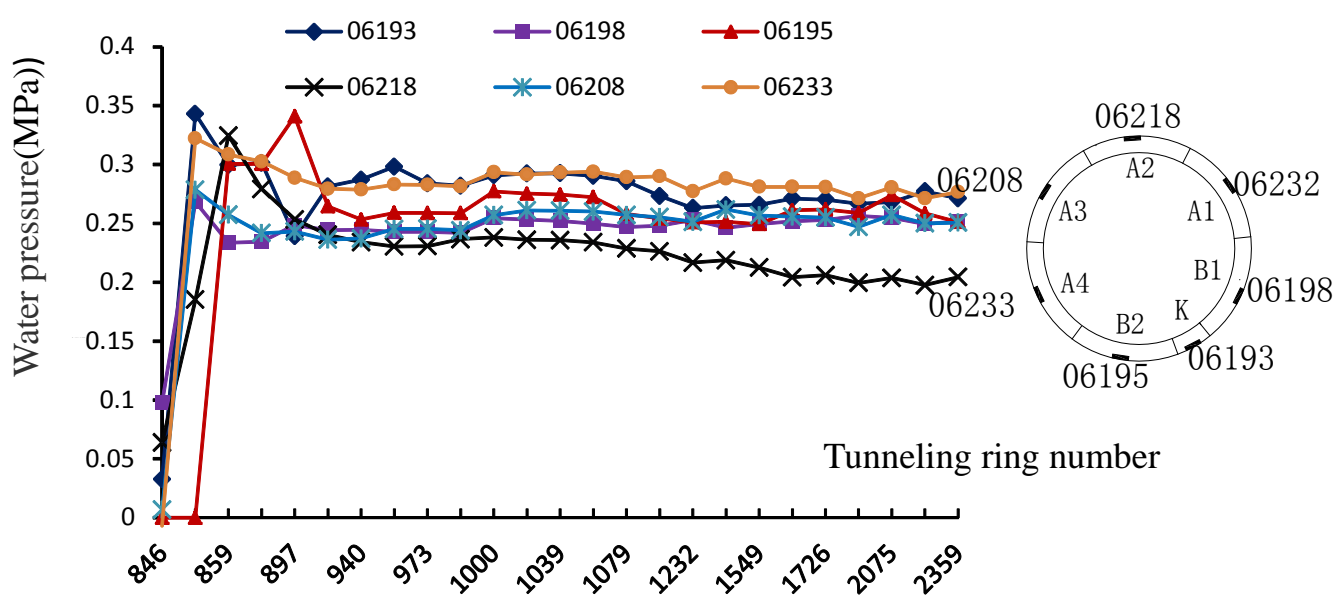

(b) 845 ring water pressure with time dynamic curve

Fig. 1 Dynamic curve of water pressure

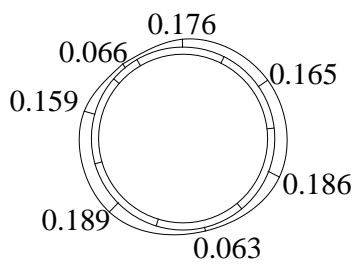

(a) 429 ring water pressure

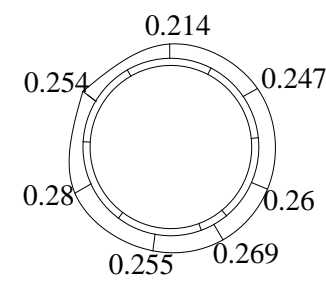

(b) 845 ring water pressure

Fig. 2 water pressure distribution in stable period ( $\mathrm{MPa}$ )

Soil pressure monitoring results and analysis As shown in Figure 3, the variation curves of soil pressure from various monitoring sections can be known. With the march of shield machine, from the segment structure formed of a locally stable state to the final formation and structure between equilibrium requires a process. The changes of the test data of each test point are in the acceleration section, the deceleration section and the acceleration stage. When the segment is separated from the tail plate protection, segment external pressure suddenly increased, segment internal force also increases. At this time for acceleration, the rate of change is maximal. This is one of the key moments in the entire stress process segment. With the external segment grouting pressure was constant. Structural adjustment and redistribution of internal force, internal force of segment values are falling, sustained and stable for a period of time, namely segment structure formation a locally stable state. With the adjustment of internal force, deformation of surrounding 
strata also, internal force is become into the re-acceleration and stable period. From the monitoring results, the segment acceleration occurs mainly in the segment of decyclization 1 10 ring, under construction load influence. It is greatly influenced by the construction load, and the pressure value of the surrounding rock in the grouting process is obviously increased. From the 20 part, the segment of rock pressure value gradually reaches a steady state, i.e. between strata and structure ultimate equilibrium.

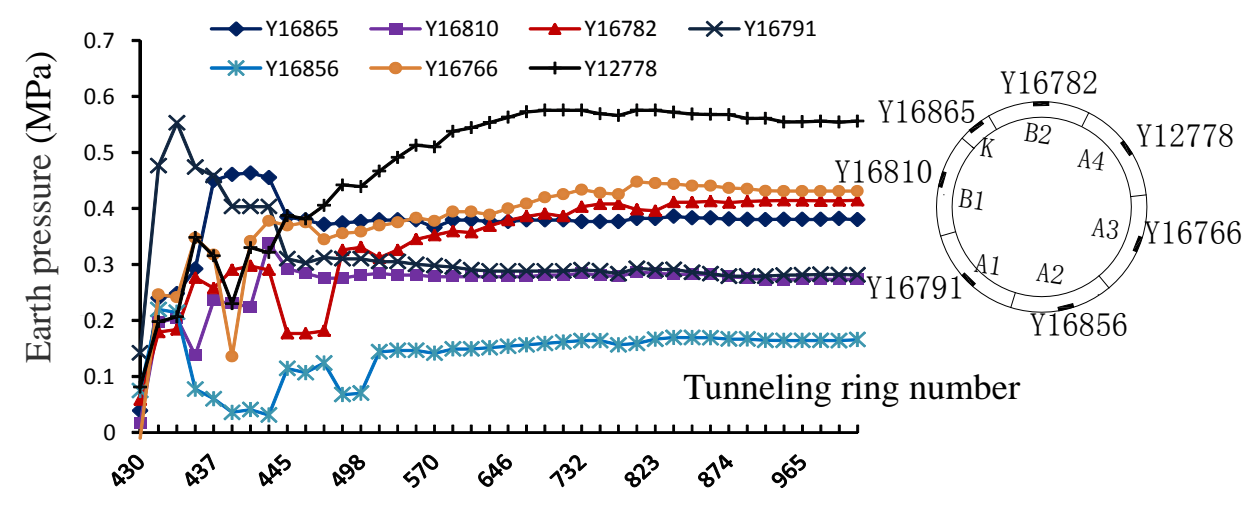

Fig. 3429 ring dynamic curve of surrounding rock pressure (MPa)

\section{Conclusion}

Through the analysis of the monitoring data, different water pressure and earth pressure, the following conclusions can be drawn.

The effect of sea water level change on the water pressure of the whole lining of the tunnel is not particularly significant; the lining water pressure is developed according to its own law of development, and has nothing to do with the sea water, such as the tide, the ocean and so on.

The role of segment structure during construction by the water soil pressure, the shield tail grouting pressure, thrust force. This will cause the structure to be subjected to the uneven force, and the structural stress is bad, and the design should pay attention.

Influence of construction of the external water pressure of segment area of about 5 18 ring, 20 ring almost entirely disappeared. The difference of the permeability coefficient of rock has a great influence on the distribution of water pressure.

The stability of tunnel surrounding rock upper part of the pressure is relatively large, while the lower part of the pressure is small. Under eccentric compression of soil, the pressure of surrounding rock is greater than that of active earth pressure.

\section{Reference}

[1]MAIR R J, TAYLOR R N, BRACEGIRDLE A. Subsurface settlement profiles above tunnels in clays. Geotechnique, 1993,43(2):315-320.

[2]WEI-I CHOU, ANTONIO BOBET. Predictions of ground deformations in shallow tunnels in clay. Tunnelling and Underground Space Technology, 2002, 17:3-19.

[3]GAO Hua-dong, Monitoring of a deep excavation in Beijing, Chinese Journal of Geotechnical Engineering. 2006(11): 1853-1856.

[4]LI Qingwei,Chen Long-hua,Cheng Jin-ming. Analysis on monitoring of deep foundation pit. Construction technology. 2008(9): 30-32.

[5]DEANE E J, BASSETT R H. The heathrow express trial tunnel. Geotechnical Engineering, 1995, 113(7): 144-156. 